\title{
PÚBLICO E PRIVADO: NOTAS CONCEITUAIS SOBRE A TRANSFORMAÇÃO DA INTIMIDADE NA INTERNET
}

Aline Maria Matos Rocha*

\section{RESUMO}

Neste trabalho, estão contemplados um cotejo acerca das definições de público e privado; e como estas esferas se articulam e são compreendidas no contexto da Internet. Sua análise privilegiou como aporte teórico a literatura disponível em Hannah Arendt, Richard Sennett, Jürguen Habermas, dentre outros. O objetivo deste artigo é disponibilizar o resultado dessas análises teóricas, tendo em vista a contribuição de sua leitura a futuros trabalhos. Diante da profusão de formas de expressão íntima na Internet, faz-se necessário aprofundar as discussões provenientes desta realidade. No ciberespaço, as dimensões do público e do privado mostram-se difusas, carentes de abordagens que convoquem suas raízes conceituais e históricas. As expressões difundidas com a cultura da Internet solicitam um olhar sobre suas características específicas, ao mesmo tempo em que a pesquisa científica deve comprometerse em ampliar as discussões daí advindas.

Palavras-chave: Público e Privado; Intimidade na Internet; Cibercultura

\section{PUBLIC AND PRIVATE: JOTTING ABOUT THE TRANSMUTATION OF INTIMACY ON THE INTERNET}

\begin{abstract}
In this work, there are included on a comparison of public and private settings, and how those terms are understood and articulated in the context of Internet. The analysis was based on theoretical literature available in Hannah Arendt, Richard Sennett, Jürguen Habermas, among others. The aim of this paper is to show the results of theoretical research and contribute to

\footnotetext{
Mestra em Sociologia pela Universidade Federal do Ceará. Professora da Universidade de Fortaleza (UNIFOR). alinemmatos@gmail.com
} 
future works. It is necessary to deepen discussions on ways of expressing intimacy on the Internet. In cyberspace, the dimensions of public and private are diffuse, lacking in conceptual and historical approaches. The expressions of culture of the Internet require a look at their specific characteristics, while that scientific research must undertake to broaden their discussions.

Keywords: Public and Private; Intimacy on the Internet; Cyberculture

\section{Introdução}

A Internet trouxe à sociedade uma variedade de mecanismos que permitem comunicação e interatividade. Nos portais de relacionamento social - como Orkut, Facebook, MySpace etc - as pessoas encontram uma forma de apresentar aos outros suas características, elementos de sua vida pessoal, encontrar amigos, realizar discussões sobre assuntos do seu interesse e manter contato com pessoas que já fazem parte de seu círculo pessoal de amizades. Além disso, há possibilidade de conquistar novos amigos, efetivar contatos profissionais, ou até mesmo encontrar um par romântico. A tecnologia disponível hoje torna possível realizar essa aproximação. E independente do espaço geográfico que ocupamos, a Internet nos faz presentes, ainda que virtualmente, dentro desses novos dispositivos de relação social.

Todo esse cenário mobiliza uma série de discussões e remete a questões que não podem passar despercebidas para quem se dedica a desvendar ou perceber com maior atenção esse fenômeno. As teorias contemporâneas apontam um horizonte novo, com perspectivas diversas, engajadas ou não, ao cenário que toma corpo: existem abordagens que conclamam o potencial inovador e o poder gregário das novas mídias; assim como existem aqueles que enfatizam o caráter atomista e individual da sociabilidade no contexto virtual.

Durante o estudo ora apresentado, procurei não perder de vista as determinações históricas que fizeram com que o fenômeno da exposição de intimidades viesse à tona. Por isso, foram analisadas as implicações que vieram a transformar, no decorrer do tempo, o significado da vida privada dos sujeitos, bem como seus modos de percepção e valorização da vida íntima. Esses aspectos são ressaltados com o objetivo de contextualizar o objeto, já que os parâmetros e códigos de conduta individuais, evidentemente, variam ao longo da história. 
Neste artigo, serão discutidos aspectos relacionados às esferas pública e privada, as quais não poderiam passar despercebidas na análise sobre as relações e expressões que predominam no contexto das novas tecnologias, em especial no uso da Internet.

Sobre a importância desta análise, Thompson (2005, p. 72) afirma que “o desenvolvimento dos meios de comunicação criou novas formas de interação, novos tipos de visibilidade e novas redes de difusão de informação no mundo moderno [...] que alteraram o caráter simbólico da vida social [...]" - grifos meus. É desta forma que, segundo ele,

\footnotetext{
Precisamos repensar o significado do ‘caráter público' hoje, num mundo permeado por novas formas de comunicação e de difusão de informações, onde os indivíduos são capazes de interagir com outros e observar pessoas e eventos sem sequer os encontrar no mesmo ambiente espaço-temporal. (THOMPSON, 2005, p. 72).
}

Nessa perspectiva, realizo neste trabalho um cotejo sobre o significado das noções de público e privado, as quais foram se redimensionando ao longo do tempo, procurando evidenciar como essas transformações são importantes para a compreensão das novas formas de expressão que encontram na Internet seu principal meio de difusão. Este estudo resulta de um trabalho de investigação teórica sobre o tema em questão, o qual subsidiou uma pesquisa qualitativa de campo, realizada com jovens participantes do portal Orkut em Fortaleza-CE.

\section{As noções clássicas de público e privado}

Os termos público e privado, na língua portuguesa, têm vários significados. Ao público pode-se atribuir o sentido de algo que pertence ao governo, ao estado, a uma coletividade, assim como denomina um conjunto de pessoas com características e interesses comuns. O privado, por sua vez, configura-se como algo pertencente a um indivíduo particular, de caráter restrito e confidencial. Àquilo que deve ser afastado do conhecimento público, de ordem pessoal, íntima e pertencente a um domínio não governamental.

Estas definições dos termos público e privado servem como ponto de partida da discussão a ser tratada neste item. Tendo como referência a teoria de Hannah Arendt, procuro evidenciar como a mudança na noção dos termos público e privado reflete uma profunda transformação das relações a serem efetivadas nestas esferas a partir da modernidade, mais especificamente, com o advento da sociedade burguesa.

Indo buscar as bases de sua reflexão no pensamento grego, Arendt (2005) descreve como a diferenciação entre público e privado era condição necessária para que o cidadão 
exercesse suas atividades na polis e fruísse de sua condição verdadeiramente humana. Conforme a autora, a máxima do pensamento grego, verificada na expressão que classifica o homem como sendo, por natureza, um animal político (zoon politikon) fora interpretada de maneira equivocada por alguns dos grandes nomes do pensamento antigo, como S. Tomás de Aquino e Sêneca. Segundo termos presentes em suas obras, a tradução da expressão aristotélica zoon politikon é interpretada como sendo o homem um animal social. (ARENDT, 2005).

Entretanto, de acordo com o pensamento grego, a condição social do homem lhe era inerente e não se diferenciava das formas gregárias de vida dos outros animais. A associação com outros de sua espécie era para o homem um imperativo biológico e não condição essencial de sua vida humana. Já a condição de "animal político", ou seja, "a capacidade humana de organização política não apenas difere mas é diretamente oposta a essa associação natural cujo centro é constituído pela casa (oikia) e pela família”. (ARENDT, 2005, p. 33). É nesse centro que se encontra o reino das necessidades, as quais são atendidas através do trabalho, enquanto o público seria o reino da liberdade de expressão da individualidade humana, onde, mediante a ação (práxis) e o discurso (lexis) o homem encontraria as bases para o desenvolvimento de sua condição essencialmente humana. É somente através da conquista da satisfação das necessidades biológicas e referentes à manutenção da vida (esfera privada) que o indivíduo ascenderia à esfera pública para exercer as atividades que o diferenciam dos outros animais. (ARENDT, 2005).

Contudo, ao longo da exposição de seu pensamento, Arendt nos mostra que, na modernidade, passamos a contar com uma outra esfera: a social. Conforme a teoria arendtiana, é importante ter em mente que as noções clássicas de público e privado, contidas no pensamento grego, e o abismo outrora existente entre essas esferas deixou de existir a partir da modernidade. A linha divisória que estabelecia a nitidez do público e do privado passou a ser menos perceptível nas sociedades modernas. É sobre este aspecto que a reflexão de Arendt se torna indispensável a este estudo.

Segundo o pensamento desta autora, na esfera social, passaram a ser admitidos assuntos que, na sociedade antiga, eram restritos à esfera doméstica e privada. Deste modo, a natureza da esfera pública, na Modernidade, assume características distintas daquelas conhecidas e legitimadas pela esfera pública em seu sentido clássico. A esfera pública moderna passa a comportar assuntos que não eram concebidos como sendo públicos e, principalmente, políticos. Por isso, diz-se que a esfera pública foi “engolida" pela esfera 
privada. Nas palavras de Arendt,

A passagem da sociedade [...] do sombrio interior do lar para a luz da esfera pública não apenas diluiu a antiga divisão entre o privado e o político, mas também alterou o significado dos dois termos e a sua importância para a vida do indivíduo e do cidadão, ao ponto de torná-los quase irreconhecíveis. (ARENDT, 2005, p. 47).

Essa alteração do significado dos termos público e privado tem importância fundamental para a análise das características do que hoje conhecemos como sendo o privado. É fundamental observar que o público fora absorvido pela esfera social, a qual traz consigo aspectos que eram considerados restritos à vida privada. Deste modo, a privatividade passa a assumir um outro sentido, distinto do clássico, no qual era definida como:

[...] literalmente um estado no qual o indivíduo se privava de alguma coisa, até mesmo das mais altas e mais humanas capacidades do homem. [...] Hoje não nos ocorre, de pronto, esse aspecto de privação quando empregamos a palavra "privatividade"; e isto, em parte, se deve ao enorme enriquecimento da esfera privada através do moderno individualismo. (ARENDT, 2005, p. 48).

Assim, tem-se que esse aspecto "privativo" da esfera privada passa a ser considerado oposto à esfera social, não à esfera pública em seu sentido clássico. Para Arendt (2005, p. 48), “o que hoje chamamos de privado é um círculo de intimidade cujos primórdios podemos encontrar nos últimos períodos da civilização romana [...]”. A privacidade moderna tem como função proteger aquilo que é íntimo. Ou seja, como o público fora esvaziado de seu sentido original, e a denominada esfera social passou a assumir o que antes era considerado como assunto privado, a esfera privada passa a se caracterizar, essencialmente, por conteúdos da subjetividade humana, os quais encontraram expressão significativa na arte, na poesia e na música modernas.

Diante dessa concepção, é possível perceber como se deu parte do processo de transformação dos sentidos das esferas pública e privada, e como essa leitura é importante para o melhor entendimento do que hoje é considerado como privacidade e publicidade, ou seja, dos assuntos que são admitidos numa ou noutra esfera.

Conforme Arendt, a esfera privada fora enriquecida pelo individualismo moderno, onde o sujeito passa a investir nos aspectos privados de sua existência. Atualmente, o que se vê na Internet é um reflexo desse investimento. Entender o processo de valorização dessa visibilidade é, também, verificar as transformações trazidas pelo desenvolvimento das instituições modernas.

\section{Da invisibilidade à visibilidade: o redimensionamento do sentido de privacidade}


Habermas também se dedica à análise da transformação do sentido clássico de público e privado. Em sua obra Mudança estrutural da esfera pública (1984), ele fornece a análise de um contexto mais específico, já que apresenta um estudo centrado na reestruturação da esfera pública, reconhecendo-a como uma categoria da sociedade burguesa. Ele verifica as transformações que foram, com a passagem ao modo de produção capitalista, reconfigurando a esfera pública e, por consequência, a esfera privada.

Sua interpretação sobre a admissão na esfera pública dos assuntos que outrora estavam restritos à dimensão privada (oikia) - o que viria a constituir a esfera social converge com o pensamento de Arendt. Contudo, ele acrescenta que

\begin{abstract}
A atividade econômica privatizada precisa orientar-se por um intercâmbio mercantil mais amplo, induzido e controlado publicamente; as condições econômicas, sob as quais elas ocorrem agora, estão fora dos limites da própria casa; são, pela primeira vez, de interesse geral. É nessa esfera privada da sociedade que se tornou publicamente relevante que Hannah Arendt pensa quando ela caracteriza, em contraposição à sociedade antiga, a relação moderna entre esfera pública e esfera privada mediante a formação do 'social'. (HABERMAS, 1984, p. 33).
\end{abstract}

A esfera pública burguesa, segundo o autor, passou a ser formada a partir do seu interesse em se contrapor ao Estado - que outrora não partilhava de todos os interesses burgueses - a fim de que fosse criado um estado de direito que regulamentasse as relações de troca, as quais passaram a ter predomínio e relevância social. (HABERMAS, 1984).

$\mathrm{Na}$ leitura de Habermas (1984), reivindicações desta natureza não tiveram antecedentes históricos. Os conflitos de poder entre os estamentos eram negociados e equilibrados através da autoridade do soberano ou dos senhores feudais. A partir do séc. XIII, para o autor, essa prática leva a uma dicotomia entre os estamentos dominantes e o poder do soberano. Na Inglaterra, com o estabelecimento do parlamento, houve uma relativização da mediação dos estamentos pelo monarca. Contudo, mesmo diante desse equilíbrio de forças, esse modelo não poderia mais afirmar-se como estado dominante numa economia que passava a ser baseada nas relações de troca.

$\mathrm{Na}$ descrição habermasiana, essas mudanças por que passava a esfera pública também trouxeram consigo uma maior autonomia do aparelho do Estado perante à esfera pessoal do monarca. Este já não incorporava o poder de forma tão plena, e a sociedade de corte passava, paulatinamente, a dividir seu cenário com a cidade. De acordo com Habermas, “à medida que 'a cidade' assume suas funções culturais, modifica-se não só o sustentáculo da esfera pública, mas ela mesma se modifica”. (HABERMAS, 1984, p. 47). 
Com relação à especificidade desta discussão, é importante frisar que Habermas (1984) revela - para além dessas mudanças de ordem econômica e macrossocial - que a esfera íntima da pequena família é o local em que se originou historicamente a privacidade. No entanto, em seu sentido antigo, a privacidade (o privado) era o domínio destinado ao reino das necessidades e da sobrevivência. Já o sentido moderno de privado evoca "uma interioridade livre e satisfeita", como significado mesmo de um gozo particular de experiências provenientes da subjetividade. E aquele sentido antigo de atendimento às necessidades materiais de sobrevivência estaria praticamente excluído desse domínio familiar e íntimo da privacidade. "À medida que a troca de mercadorias rebenta com os limites da economia doméstica, a esfera restrita da família se delimita perante a esfera da reprodução social [...]". (HABERMAS, 1984, p. 43).

Nesse sentido, tem-se que a esfera privada passa a ser duplamente classificada, onde em suas instâncias "o status de homem privado combina o papel de dono de mercadorias com o de pai de família, o de proprietário com o de 'homem' simplesmente". (HABERMAS, 1984, p. 44). O privado passa, portanto, a nomear esses dois papéis, de maneira simultânea.

\subsection{O processo de privatização e individualização}

Diante desse contexto de mudança na estrutura da esfera pública, Habermas (1984) passa a definir o processo de institucionalização de uma privacidade ligada ao público, na família burguesa. E sobre esse aspecto ele fala da existência das necessidades de um públicoleitor burguês, que se satisfazia na leitura de dramas burgueses e romances de natureza psicológica. Segundo o autor,

[...] As experiências, sobre as quais um público, que apaixonadamente tematiza a si mesmo, busca no raciocínio público das pessoas privadas entendimento mútuo e esclarecimento, essas experiências fluem de fontes de uma subjetividade específica: o seu lar é, em sentido literal, a esfera da pequena-família patriarcal. (HABERMAS, 1984 , p. 60, grifo meu).

Habermas fala de uma "nova vida familiar", proveniente da interioridade da família nuclear burguesa, que se distingue da vida relacional e comunitária das grandes famílias, estas mais restritas a costumes ligados ao ambiente rural e pré-burguês, distinto daqueles que se formavam no ambiente citadino. Para ilustrar seu raciocínio, ele registra a mudança no estilo arquitetônico das casas: 
[...] A privatização da vida pode ser observada numa alteração do estilo arquitetônico: 'nas casas recém-construídas foram feitas determinadas mudanças arquitetônicas. A galeria de teto mais alto, com barrotes em cima, [...] sai então de moda. A sala de jantar e os quartos de dormir passaram a ser feitos da altura de um andar, enquanto que as diferentes finalidades a que o antigo salão devia servir foram distribuídas por numerosos quartos de tamanho comum [...]"”. (TREVELYAN apud HABERMAS, 1984, p. 61).

O que se observa é que o espaço destinado à convivência em comum diminuiu, tornando-se cada vez menor. Ao contrário, "os quartos privados de cada um dos membros da família tornaram-se cada vez mais numerosos, sendo decorados de modo característico. $\mathrm{O}$ isolamento do membro da família [...] passa a ser considerado algo positivo". (HABERMAS, 1984, p. 61).

Nesse processo, observa-se que o indivíduo passa a ganhar seu espaço próprio no interior das casas, o que é evidência de uma valorização e maior delimitação do eu. No interior da família burguesa, a individualidade e a subjetividade das pessoas passam, então, a ser forjadas sob a institucionalização das relações privadas da vida familiar burguesa - esta sendo reconhecida como uma esfera que "elabora intimamente a humanidade". (HABERMAS, 1984, p. 64). Habermas dirá que a forma literária que dá expressão a estas mudanças é a correspondência epistolar - e ainda, o diário íntimo pessoal. As cartas que eram trocadas entre amigos, enamorados, familiares, passam a retratar de maneira mais expressiva e demarcada a subjetividade e personalidade de seus remetentes.

A análise de Habermas define a concepção da esfera pública, e a consequente redefinição do privado, sob a perspectiva da emergente burguesia. O modus vivendi que é retratado em sua teoria demonstra como a burguesia precisou, conforme a natureza de suas relações materiais, de uma redefinição da esfera pública que se adequasse aos interesses de sua forma específica de relacionar-se nesta esfera, sob um modo de produção predominantemente capitalista. Entretanto, é necessário abordar que o novo código de relações que passava a dominar o espaço público, em sua análise, estava restrito ao estamento burguês da sociedade, o qual deixava de lado as classes populares e menos abastadas, como a operária, por exemplo. Deste modo, investigando outras leituras - como as de Prost (2009) que ilustram o histórico de transformações das esferas pública e privada é possível constatar que esse processo não se deu de forma homogênea e simultânea no corpo social. O conjunto dessas mudanças deu-se de maneira diferenciada entre as diversas camadas sociais que passaram a se constituir sob o signo das relações de troca de mercadorias.

Partindo do mesmo exemplo dado por Habermas (1984), o qual ilustrava a arquitetura dos imóveis burgueses, é importante ressaltar que, em contraposição a estes, até o 
final do séc. XIX e início do séc. XX, as moradias populares eram distintas do estilo burguês:

[...] A essas residências amplas, a essas casas 'burguesas', opunham-se as moradias populares. Operários e camponeses se aglomeravam em habitações de um ou dois cômodos. No campo, muitas casas tinham apenas um aposento, onde a família cozinhava e dormia. Os médicos que, por volta de 1900, estudaram as condições de higiene das casas rurais, [...] nos descrevem esses aposentos coletivos, onde às vezes se amontoam quatro camas, cada qual para, no mínimo, duas pessoas. (PROST, 2009, p. 54).

Observe-se que o recorte temporal de Prost é mais recente do que o contexto apresentado por Habermas, situado entre os séc. XVII e XVIII, o que indica que o capitalismo não extinguiu a separação entre as classes sociais ao longo do tempo. Na análise de Prost, o séc. XX, mais precisamente em sua segunda metade, é tido como o século da conquista do espaço, advinda com o processo de democratização política e social.

Com a introdução de políticas públicas de incentivo à construção de imóveis populares, na segunda metade do século XX, a oferta de habitação ampliou-se de forma considerável $^{1}$. E esse tipo de imóvel deveria atender a padrões mínimos de espaço e equipamentos, para que o poder público pudesse conceder seu apoio. De acordo com essas normas, "uma peça habitável não pode ter menos de nove metros quadrados. Uma casa possui, além da cozinha, uma sala em comum, um quarto para os pais e pelo menos um quarto para dois filhos, banheiros internos, um local para lavagem de roupas [...]". (PROST, 2009, p. 58). Todo esse processo de transformação no interior das moradias deve-se, dentre outros fatores, a uma demanda do indivíduo, o qual passava a reivindicar seu próprio espaço.

Ressaltar as mudanças ocorridas no interior das moradias ilustra uma das importantes transformações na concepção das esferas pública e privada no decorrer do tempo. O processo de individualização por que passou o sujeito ao longo dessas mudanças foi dependente dessa oferta de espaço próprio e, ao mesmo tempo, esteve ancorada na demanda do sujeito por uma delimitação daquilo que lhe era mais particular: o cultivo de si mesmo.

Apesar das limitações acarretadas pelas diferenças de classe, o capitalismo provocou uma revolução na maneira do sujeito perceber-se como dotado de algo que lhe era inerente e que deveria ser preservado. Prost $(2009$, p. 64) destaca que "se há uma nova ideia na França, [a partir da segunda metade do século XX] é a de que os indivíduos têm o direito de levar a

1 É pertinente acrescentar que o autor se refere ao contexto francês quando fala nas transformações ocorridas nas políticas de habitação. Considero válido apresentar sua análise, já que o teor dessas mudanças possui alcance indeterminado. Além disso, a importância dessa leitura deve-se ao destaque no processo de individualização, e o surgimento de uma demanda de espaço próprio ao indivíduo. Cabe destacar também que a análise deve ser relativizada face as precárias condições de moradia dos pobres no Brasil. 
vida privada como bem entenderem. Durante toda a primeira metade do século $\mathrm{XX}$, a vida privada se viu praticamente presa ao controle da coletividade [...]".

Entretanto, foi preciso um certo tempo para que o indivíduo - já tendo conquistado seu espaço - pudesse levantar-se contra o domínio da instituição familiar e determinar o que seria melhor para sua vida e seu futuro. Mesmo diante da conquista do espaço, não se pode negar que a família exerceu - e ainda exerce, até certo ponto - grande controle sobre o destino de seus membros, sendo necessária uma mudança ainda maior nos costumes e valores que davam (ão) sustentação ao código de conduta individual.

\subsection{Público e Privado: espaços de transição}

Ainda tendo como referencial as análises de Antoine Prost (2009) sobre as esferas pública e privada, merece destaque o fato de que a história da vida privada no século XX é demarcada por dois movimentos: a transferência do trabalho dos espaços domésticos para locais impessoais; e a conquista do espaço não somente físico, mas pessoal, do indivíduo dentro da família.

A diferenciação dos espaços público e privado no século $\mathrm{XX}$ foi realizada tendo como suporte uma ampla e complexa teia de articulação e convivência entre estas duas esferas, não tendo sido marcada por uma oposição radical entre elas. Parte desta articulação ganha contorno nos espaços de entrecruzamento da vida privada e pública, demonstrada pela necessidade de uma convivência diária do indivíduo numa e noutra esfera. Ele ilustra essa necessidade através da organização coletiva dos espaços para uso comum nas grandes cidades, como os transportes coletivos - utilizados no cotidiano de quem se desloca de casa para o trabalho diariamente. De acordo com o autor, o bairro, tomado como um contexto mais particular no seio das cidades, é tido como espaço de transição por natureza, e como lugar de conhecimento mútuo. "Sair pelo bairro é, pois, se expor". (PROST, 2009, p. 101).

Em contraposição a esse movimento de transição e convivência proporcionada pelo cotidiano nos bairros, Prost (2009) destaca que grande parte dessa sociabilidade e reconhecimento foi suprimida pelas características da urbanização contemporânea. Com o aumento crescente da população das grandes cidades, essas relações ganharam um maior grau de complexidade e a vida nos conglomerados urbanos passou a exigir de seus cidadãos um retraimento, de certa forma involuntário, ocasionado pelo nível de ocupações diárias de seus habitantes, bem como numa mudança na arquitetura das novas moradias. 
É interessante mostrar como a transformação desses aspectos da vida cotidiana, aparentemente simples, proporciona um entendimento sobre a configuração das novas formas de sociabilidade que sobressaem desse contexto, como por exemplo, aquelas que se realizam tendo como suporte a tecnologia. Todo esse horizonte oferece uma explicação possível para o aumento gradativo que vemos nas relações sociais mediadas pela tecnologia de comunicação.

Em paralelo a isso, faz-se necessário apontar que Prost não considera válido concluir que o público foi englobado pelo privado. Em sua interpretação, as novas sociabilidades, apesar de serem pautadas, cada vez mais, pela introdução e troca de aspectos particulares sobre a personalidade dos indivíduos nela envolvidos, não significam o esvaziamento completo das normas e moral específicas da dimensão do público. Conforme o autor,

[...] é incontestável que há um esforço para reintroduzir as particularidades pessoais na vida social. Mas isso não transforma a vida pública em vida privada. À medida que nossa sociedade adotou formas reguladoras mais brandas para garantir sua coesão, os códigos sociais se tornaram mais sutis e mais discretos, mas sempre persistindo: não se pode dizer qualquer coisa a um superior ou a um colega, nem se vestir de qualquer jeito. Para se expressar na esfera do público, a pessoa deve [ainda] recorrer a esses códigos mais complexos, porém igualmente efetivos [...]. (PROST, 2009, p. 123).

A leitura de Prost oferece uma explicação coerente sobre as mudanças e introdução de outros referenciais à orientação dos sujeitos na formação e estabelecimento de suas relações sociais. Para o autor, ao mesmo tempo em que houve um enriquecimento na dedicação e certa prioridade que o sujeito moderno atribui ao privado, a vida pública também "penetra, infiltra e modela o recôndito mais secreto e mais íntimo da vida privada". (PROST, 2009, p. 124). Por outro lado, não se pode deixar de lado as leituras que dão conta desse movimento de valorização e cultivo do privado como características de uma sociedade presa ao domínio de uma visão intimista.

No próximo item, discutirei o processo de transformação sofrido na noção de intimidade e sua dependência da mudança ocorrida nas esferas pública e privada.

\section{A transformação da intimidade}

Dando continuidade ao processo de redimensionamento das esferas pública e privada, é importante trazer para a análise em questão a abordagem que Sennett (1988) faz sobre esses domínios. De acordo com esse autor, na modernidade, os papéis sociais que o homem desempenhava, assim como sua vida pública, foram gradualmente diminuindo em 
favor de sua vida particular, estando o sujeito voltado para sua privacidade e intimidade.

Para ele, algumas transformações ocorridas desde o séc. XVIII trouxeram mudanças na visão que as pessoas tinham de privacidade. No Antigo Regime ${ }^{2}$, existia uma separação bem definida entre os espaços da vida pública e da vida privada. Ou seja, naquele período, essas instâncias se encontravam em certo equilíbrio, e aquilo que pertencia ao domínio íntimo não se emaranhava às questões da esfera pública. Assim, as pessoas se relacionavam em domínio público sem que seus códigos de significação pessoal interferissem no que dizia respeito ao trato de questões impessoais.

É preciso deixar claro que Sennett não considera que a vida pública começou no século XVIII, mas que precisamente neste século a vida pública ganha uma nova versão, a qual, segundo ele, está “centralizada em torno de uma burguesia em ascensão e de uma aristocracia em declínio". (SENNETT, 1988, p. 68).

As cidades passaram a se desenvolver como núcleos comerciais e suas populações aumentaram num nível jamais visto, obrigando seus habitantes a conviverem perante estranhos e forasteiros. No estudo de Sennett, as expressões "estranho" e "forasteiro" servem para indicar duas categorias de desconhecidos: a primeira indicava aqueles a quem não se conhecia as origens de imediato, como seus antepassados, familiares, classe social, etc; já a segunda caracteriza aqueles cuja razão do desconhecimento pode ser identificada de imediato, como os estrangeiros, que por razões de traços físicos, ou linguagem distinta, se pode identificar de pronto. Por esta razão, passou-se a estabelecer códigos de conduta que preservassem a dimensão particular e íntima do indivíduo, ao mesmo tempo em que este se relacionava em público.

Conforme Sennett (1988), o desenvolvimento das cidades e do capitalismo industrial foram fatores importantes para as mudanças no paradigma das relações entre o público e o privado. Com o número de seus habitantes crescendo vertiginosamente, as cidades tornavamse lugares de estranhos. O comércio, com o desenvolvimento da indústria e a difusão do consumo em massa, passa a transformar as relações de troca, tornando-as mais distanciadas. Os produtos passam a ser expostos em grandes magazines e os preços fixos tornam desnecessários o "ritual da pechincha", e, consequentemente, a relação entre vendedor e comprador.

Com isso, as cidades cosmopolitas e o comércio de bens e serviços acabaram por

Sennett esclarece que seu uso da expressão Antigo Regime, assim como o fez Tocqueville, sinaliza o espaço de tempo compreendido pelo século XVIII, em especial ao período do estabelecimento da burocracia comercial e administrativa no desenvolvimento das nações. (SENNET, 1988, p. 67). 
contribuir para o distanciamento espacial e pessoal dos cidadãos. Estes fatores desencadearam transformações das esferas pública e privada, fazendo com que os indivíduos passassem a supervalorizar suas relações íntimas, em detrimento daquelas que manteriam com "estranhos". Tal atitude fez com que as pessoas das grandes cidades, inseridas num "mundo de desconhecidos", se obrigassem a desvendar certos traços de sua personalidade e vida íntima para que pudessem desenvolver e estabelecer relações consideradas "confiáveis" entre si. De acordo com Sennett (1988, p. 14), “o sistema de expressão pública se tornou um sistema de representação pessoal; uma figura pública apresenta aos outros aquilo que sente, e é essa representação de seus sentimentos que suscita a crença".

A visão de Sennett a respeito de algumas dessas transformações torna-se útil para a compreensão da divulgação de certos conteúdos íntimos por parte dos indivíduos que publicam na Internet. Através de diversos meios de interação, as pessoas publicam seus perfis como forma de conquistar novos amigos na rede. Expor características e gostos pessoais, bem como seus cotidianos e desabafos, é uma forma de "apresentar-se" ao conhecimento dos outros. Nas palavras de Sennett,

O desejo de revelar a própria personalidade no trato social e de avaliar a ação social em termos daquilo que esta mostra das personalidades das outras pessoas pode ser rotulado de diversas maneiras. É, primeiramente, um desejo de se autenticar enquanto ator social por meio de suas qualidades pessoais. $\mathrm{O}$ que torna uma ação boa (isto é, autêntica) é a personalidade daqueles que nela se engajam, e não a ação em si mesma. (SENNETT, 1988, p. 23 - grifo meu).

No ambiente da Internet, essa prática é trivial. Uma vez que as relações entre as pessoas são mediadas pelo computador, é possível constatar que a mostra de detalhes de suas vidas e personalidades é um meio válido para que se legitime uma relação virtual de amizade. Desprovidos, em geral, de convivência face-a-face, os sujeitos expõem sua privacidade e lêem detalhes da intimidade alheia como forma de estabelecerem entre si relações de "confiança", baseadas em afinidades. Em minha pesquisa sobre o diarismo virtual ${ }^{3}$ essa prática ficou bastante evidenciada, uma vez que os sujeitos revelaram que seus blogs eram portadores de sua personalidade e subjetividade, e ao identificarem outras personalidades cujos interesses convergiam com os seus, havia chances potenciais de se efetivar uma relação virtual de amizade.

O trato social, no ambiente da Internet, parece ser permeado por esse jogo de revelações mútuas, onde cada um mostra aquilo que deseja que o outro saiba a respeito de sua 
personalidade. É desta forma que as relações virtuais vão se efetivando, as redes de sociabilidade vão se formando, e determinados aspectos da personalidade e intimidade dos indivíduos tornam-se moeda corrente na construção de suas relações.

A proximidade, nesse ambiente, conta com a mediação da tecnologia para efetivar-se e caracteriza-se pela facilidade com que os sujeitos encontram dispostas as informações que julgam precisar para construir seus vínculos. Dispositivos de publicação e interação - como os blogs, os fotologs e os sítios de relacionamento virtual - promovem tanto a intercomunicação como a exibição de imagens e conteúdos dos sujeitos a respeito de si mesmos. Tais práticas revelam a necessidade que determinados sujeitos sentem de expor aos outros as características que fazem parte daquilo que delineia suas atividades, pensamentos, gostos e atitudes, tornando suas qualidades - e até mesmo seus defeitos - verdadeiros atrativos para que os interessados em seus perfis se identifiquem e possam desenvolver uma possível relação de amizade e troca de intimidades.

No ambiente virtual, a sociabilidade é efetivada, e o sujeito encontra, na revelação de certos aspectos de sua personalidade, uma forma válida de apresentar-se ao universo potencial de pessoas que poderão interagir com ele e partilhar interesses em comum. Embora esse dito "espaço do outro" esteja de certa forma bem delimitado, ele torna-se evidente no contexto das interações virtuais e é uma instância pronta para estabelecer contatos e relações em torno de afinidades. É desta forma que o espaço público passa a ser compartilhado e redefinido como uma esfera de confronto de diversas opiniões, interesses e personalidades que interagem na rota de fluxos ininterruptos da Internet.

\subsection{O privado e sua dimensão espetacular}

Torna-se relevante apontar como o processo de individualização trouxe consigo as evidências do que é hoje o fenômeno de exposição da privacidade. É preciso indicar o quanto esse processo é importante à compreensão do que é conhecido atualmente como "desinstitucionalização", tendo em vista que muitos sociólogos, como Bauman (2001), por exemplo, dão conta desse fenômeno como sendo, em parte, determinado pela ausência de parâmetros institucionais "claros" para que o indivíduo possa estabelecer-se e orientar sua conduta.

Nesse sentido, faz-se necessária a introdução de um outro referencial teórico de grande valia à tentativa de compreensão empreendida durante este estudo. Trata-se da 
contribuição do citado autor, cujo pensamento fornece parâmetros esclarecedores sobre o processo de desinstitucionalização das estruturas de sentido que faziam parte da formação do sujeito, assim como das transformações sofridas nas esferas pública e privada.

Segundo Bauman, no último estágio da modernidade ${ }^{4}$, o domínio privado passou por uma reversão. Antes, a esfera privada era caracterizada pelo "direito ao segredo" - era legítimo o indivíduo resguardar-se e proteger sua intimidade da curiosidade alheia. $\mathrm{O}$ contrário ocorre atualmente, quando o privado passou a ser relacionado com o "direito à publicidade”. Sobre esse aspecto Bauman se refere ao surgimento de canais que facilitaram a abertura do sujeito ao mundo público, como os meios de comunicação de massa, cuja agenda cultural incluía programas em que o público era incitado a participar de canais em que sua opinião e acontecimentos de sua vida pessoal eram valorizados e discutidos publicamente. É nesse sentido que o indivíduo passa a dar um peso maior às suas experiências íntimas, dandolhes publicidade. (BAUMAN, 2000, p. 70-71).

O sujeito, outrora amparado em seu mundo privado, sente-se motivado a expor aquilo que gostaria que os outros soubessem a seu respeito, como forma de por em discussão suas opiniões, seus questionamentos e conflitos pessoais. Para o autor, essa reversão do privado não se dá sem a redefinição do público, cujo sentido "foi transformado em território onde são exibidos os assuntos particulares e bens pessoais”. (BAUMAN, 2000, p. 71).

Tendo similaridade com o pensamento de Sennett, Bauman reforça a ideia de que anteriormente os eventos de natureza coletiva não podiam ser reivindicados como assunto privado. Para ele, o “"público’ fora despojado de seus conteúdos diferenciais e ficou sem agenda própria - não passa agora de um aglomerado de problemas e preocupações privados". (BAUMAN, 2000, p. 72).

É possível perceber características importantes sobre as transformações que ocorreram no corpo social nos últimos tempos, sobretudo no que diz respeito à reversão dos valores que instituíam a esfera privada como resguardada do olhar alheio. No entanto, é necessário ter em mente que o fenômeno analisado é processual, não sendo possível atribuir sua ocorrência a um fator determinante.

Estando diante de um blog, de um fotolog ou de qualquer outro meio em que se veiculem atributos e discursos pessoais na Internet, não é difícil encontrar pessoas que classificam os sujeitos que se utilizam desses meios virtuais de "narcisos", ou de que eles

4 Esse último estágio do período moderno pode ser compreendido como a segunda metade do século XIX, momento em que os ideais modernos passaram a ser questionados com maior vigor. 
estão apenas à procura de exibição e entretenimento gratuitos. Entretanto, para se chegar a uma constatação como essa, não se faz necessária uma reflexão mais apurada, pois a superfície dos fatos fornece um caminho de fácil acesso a essa interpretação.

A opinião do senso comum em relacionar as pessoas que participam de sítios de relacionamento virtual com o mito de Narciso é bastante sintomática e reproduz um estereótipo concebido por quem, de imediato, se defronta com a prática de publicação íntima na Internet. No entanto, os rumos da análise sociológica demandam um olhar mais criterioso, sendo imprescindível observar as características que estão permeadas nessa classificação.

Ao entrar em contato com os usos da tecnologia - cada vez mais estendida aos domínios do cotidiano - o sujeito contemporâneo dispõe de meios que dão suporte às suas práticas de investimento em interesses e fatos particulares. Celulares, câmeras de vídeo e fotografia digitais, notebooks, laptops e palmtops, são instrumentos que ampliaram seus usos ao usuário comum - ávido por registrar suas experiências e publicá-las nos portais de relacionamento dos quais participa.

O sujeito, mediante esses recursos, passa a apreender com mais facilidade e instantaneidade alguns fatos e ocorrências cotidianas que ele decidirá tornar públicas ou não. Deste modo, faz-se necessário discutir os principais aspectos que se fazem presentes em estudos realizados sobre problemáticas que evidenciam a questão do narcisismo em diferentes contextos, e sobre os quais é possível observar pontos de convergência adequados à compreensão da prática dos sujeitos que decidem dar publicidade a subjetividades e fatos de suas vidas cotidianas na Internet.

\subsection{O narcisismo contemporâneo}

Narciso, como contado no mito grego, é um jovem que, ajoelhado diante de um lago, arrebata-se diante de sua própria beleza, a qual vê refletida na água. Tudo com o que se importava era em contemplar-se, e quando curva-se para acariciar sua imagem na superfície do lago, cai e afoga-se. Mas, para Sennett (1988), o sentido do mito é algo além do auto-amor, e conforme seu pensamento ele

[...] tem um duplo sentido: a sua auto-absorção evita que tenha conhecimento a respeito daquilo que ele é e daquilo que ele não é; esta absorção também destrói a pessoa que está engajada nessa situação. Narciso, ao se ver espelhado na superfície da água, esquece que a água é uma outra coisa, que está fora dele próprio, e desse modo se torna cego a seus perigos. (SENNETT, 1988, p. 395). 
Dispensando a acepção psicanalítica, o termo narciso, para Sennett (1988), está fortemente relacionado ao constante processo de investimento na vida privada e à psicologização do social a que o indivíduo cosmopolita se submeteu. Durante esse processo, o sujeito perderia a noção dos domínios do outro; e, já que intensamente voltado para questões de cunho particular, torna-se alheio a assuntos que fogem aos seus interesses pessoais.

O narcisismo, no sentido clínico, diverge da idéia popular do amor de alguém por
sua própria beleza; num aspecto mais estrito e como um distúrbio de caráter, é a
preocupação consigo mesmo que impede alguém de entender aquilo que é inerente
ao domínio do eu e da autogratificação e aquilo que não lhe é inerente. Assim, o
narcisismo é uma obsessão com "aquilo que esta pessoa, este acontecimento
significam pra mim". (SENNETT, 1988, p. 21).

Para Sennett, o narcisismo é o oposto do auto-amor, é antes um modo de ser, no qual são apagadas "a linha divisória entre o eu e o outro". E através desse apagamento o sujeito não entroniza nada de novo, fazendo com que o outro passe a ser uma experiência negativa, a menos que este possa lhe refletir. É desta forma que, na análise de Sennett,

O eu formado nesses termos começa a ressoar com a história da personalidade e da cultura que tem nos ocupado; este é um eu para o qual os limites da significação se estendem somente até onde esse espelho puder refletir; à medida que o reflexo vacile e tenham início as relações impessoais, a significação deixa de existir. (SENNETT, 1988, p. 396).

A interpretação fornecida por Sennett (1988) torna-se importante na medida em que ele considera o fenômeno do narcisismo como sendo expressão de processos sociais mais amplos, como por exemplo, a crise na redefinição do público e do entendimento que se passa a ter desta esfera. Para o autor, a histeria ocupou e mobilizou as relações sociais no séc. XIX, ao passo que neste momento é o narcisismo que passa a ser mobilizado por uma cultura descrente do público e pautada pelo sentimento intimista como medida de significação da realidade.

Em leitura mais recente, Lipovetsky (2004) afirma que os sujeitos pós-modernos detêm o poder de adotar condutas condizentes com suas escolhas pessoais, pois se encontram descomprimidos dos modelos pré-estabelecidos pelas instituições. O narciso estaria, nesse contexto, situado numa fase considerada "jubilosa e liberadora do individualismo, que vivenciava mediante a desafeição pelas ideologias políticas, o definhamento das normas tradicionais, o culto ao presente e a promoção do hedonismo individual”. (LIPOVETSKY, 2004, p. 25).

Essa visão está relacionada ao narciso inserido no contexto da pós-modernidade, considerado pelo autor como um período de transição aos tempos que ele denomina de 
hipermodernos. Para ele, a hipermodernidade, vivida atualmente, é definida como "uma sociedade liberal, caracterizada pelo movimento, pela fluidez, pela flexibilidade; indiferente como nunca antes se foi aos grandes princípios estruturantes da modernidade". (LIPOVETSKY, 2004, p. 26).

O narciso pós-moderno, passando do período de vivência da liberação de seus sentimentos individualistas, adentra no fluido contexto da hipermodernidade. Somente a partir daí é que surge, na leitura de Lipovetsky, o conceito de hipernarcisismo, resultado da inserção do sujeito num contexto ambivalente; pois se encontra num meio dotado de flexibilidade, tendo à sua disposição tanto "liberdades", como novas formas de dependência. São essas prerrogativas que acabam por transformar e redimensionar a atual concepção narcisista do indivíduo.

É daí que resultará um novo modelo de individualismo narcisista, repleto de nuanças ambivalentes. O narcisismo que caracteriza o sujeito contemporâneo possui uma consciência de responsabilidade, flexibilidade e eficiência que, de certo modo, rompe com o narciso do período pós-moderno, extremamente hedonista e libertário. Os sujeitos hipernarcisistas estão inseridos numa lógica dual, onde são, simultaneamente, "mais adultos e mais instáveis, menos ideológicos e mais tributários das modas, mais abertos e mais influenciáveis, mais críticos e mais superficiais, mais céticos e menos profundos". (LIPOVETSKY, 2004, p. 28).

A ambiência tecnológica, com toda sua instantaneidade e rapidez, remete a essa compreensão do sujeito contemporâneo. Diante dos modos de imersão e interação virtuais, os indivíduos se encontram num espaço prenhe de alternativas que lhes possibilitam o exercício de sua ampla autonomia e, ao mesmo tempo, instabilidade.

$\mathrm{Na}$ análise do fenômeno de publicação de si na Internet, não se pode perder de vista essas questões, que estão presentes na formação da subjetividade dos sujeitos na contemporaneidade, os quais têm diante de si, recursos que maximizam e transformam seus modos de expressão social. Toda essa dinâmica de auto-publicação e expressão não é somente exacerbada nos sites de relacionamento social, isso também está presente quando se vê, com frequência, a disseminação do uso das câmeras e celulares aparelhados com fotografias digitais, que retratam, reproduzem e exibem espaços da vida cotidiana das pessoas, numa dimensão espetacular.

$\mathrm{Na}$ via de fluxos da Internet, o sujeito ganha espaços para exibir esses reflexos de si, trazendo a público seus novos códigos de significação pessoal, ao mesmo tempo em que expressam os valores da lógica dual da pós-modernidade, essencialmente caracterizada por 
um misto de ansiedade e efervescência.

Desta forma, no decorrer do estudo, levou-se em consideração esse novo modo de significação pessoal, que, no ritmo da Internet, levam os sujeitos a exporem seus pensamentos e modos de vida, reproduzindo suas experiências num meio instantâneo de circulação de conteúdos, visando, através disso, elevarem-se à condição de protagonistas de suas histórias e autores de suas decisões, modos de pensar e agir. Percebe-se que os sujeitos, ao elevarem-se a essa condição, também revelam a necessidade de interagir com os outros, a fim de compartilharem opiniões sobre os assuntos que publicam. Ou seja, no fluxo de interação na Internet, a comunicação, exercida através de dois polos atuantes, se efetiva e se constitui como um elo entre os indivíduos.

Paralelo a isso, mediante o uso dos portais de relacionamento, o usuário comum da Internet tem à sua disposição uma mídia de fácil acesso e manutenção, na qual, além de expor seus interesses poderá atribuir à sua vida uma dimensão espetacularizada, já que está em exposição constante num meio de comunicação mundial. O sujeito apresenta uma vontade de expressar-se como único, através da celebração de sua identidade pessoal.

Contudo, apesar dos apelos para que se defina o fenômeno de expressão de si no ciberespaço como formas reluzentes do exibicionismo e do narcisismo contemporâneo, tem-se que as tentativas de explicação apontam para algo mais complexo, como o declínio da interioridade, por exemplo.

Sibilia (2003, p. 4), em recente estudo sobre a prática de publicação de si na Internet, adverte para a questão de que "estaríamos vivenciando um paulatino desbalanceamento na organização subjetiva, uma passagem do mundo abissal dos sentimentos [...] para uma preeminência da sensorialidade e da visibilidade instantânea". Trata-se, portanto, de uma cultura das sensações, que emana novos mecanismos de construção e reconstrução de si, onde a interioridade clássica desvanece em prol de tendências performáticas que almejam certa visibilidade.

\section{Considerações Finais}

Tendo observado o ganho de publicidade que alguns aspectos da vida cotidiana e subjetiva dos sujeitos adquire na Internet, cabe perguntar se ainda restaria algo de privado aos domínios da vida íntima das pessoas que se publicizam na rede mundial de computadores. A análise sociológica dessa prática fez ressaltar pontos pertinentes para o entendimento de tal 
fenômeno, o qual configura espaços para mútuas relações entre os indivíduos na grande rede.

É precisamente nesse sentido que cumpre verificar o processo pelo qual os indivíduos tornam visíveis certos aspectos de sua personalidade e intimidade, num jogo que os fazem delinearem-se de acordo com seus interesses pessoais. Seus valores, imagens, experiências, performances etc, ganham acabamentos que parecem buscar seduzir os olhares dos outros para si, desvelando o comércio de intimidades em que estão inseridos. De acordo com Sibilia (2003),

Todas essas tendências atuais de exposição da intimidade vão ao encontro e prometem uma vontade geral do público: a avidez de bisbilhotar e 'consumir' vidas alheias. Nesse contexto, os muros que costumavam proteger a privacidade individual sofrem sérios abalos; cada vez mais, essas paredes outrora sólidas são infiltradas por olhares tecnicamente mediados que flexibilizam e alargam os limites do dizível e do mostrável. (SIBILIA, 2003, p. 4).

Existe uma evidência que aponta para o fato de que há uma reversão dos aspectos outrora considerados íntimos em objetos de consumo público. O pensamento de Rüdiger (2000, p. 2) insere-se nessa problemática quando ele afirma que "a tendência estimulada pelas novas tecnologias de comunicação é a exposição do eu como mercadoria”. Ao contextualizar o pensamento de Lasch (1983), Rüdiger (2000, p. 2) esclarece que na questão da sedução, embutida na prática de publicização, está o fato de que "na economia de mercado, as pessoas têm de projetar uma imagem atraente e tornar-se atores conscientizados de que vivem sob o constante escrutínio de seus amigos tanto quanto de estranhos, dos colegas tanto quanto de seus superiores".

$\mathrm{Na}$ esfera das relações sociais travadas através da Internet os indivíduos têm à sua disposição mecanismos de expressão pessoal, mediante os quais ressaltam características que os façam conquistar certo número de "amigos" ou contatos que estejam em sintonia com seus interesses. A intimidade passa, então, a ser valor de troca quando inserida na dimensão das relações que se objetivam na grande rede.

O consumo da intimidade alheia ganha notoriedade no eixo das publicações da Internet. Porém, diante da visibilidade que é conferida nesse espaço, deve-se ter em mente o fato de que o sujeito se reconstrói quando decide expor suas narrativas em público, por isso, molda-se e atribui a si características que acredita estar em confluência com as identidades que circulam na grande rede.

Outra questão recorrente, presente na abordagem de Rüdiger (2000, p. 3), sugere que, no contexto das novas tecnologias, "a esfera pública virtual liga sujeitos atomizados", pois o homem foi forçado a dispersar-se e segmentar-se socialmente. É nesse sentido que a vida 
social dos sujeitos que interagem no ciberespaço ganha um novo significado, posto que o indivíduo, ao mesmo tempo em que se "afasta" de uma vida social ligada aos limites espaciais, tem a necessidade de se reintegrar nesta, ainda que virtualmente.

No entanto, apontar o afastamento da vida social não implica dizer que os sujeitos não mais possuem contatos afetivos e convívio relacional com as pessoas que os circundam, retirando-se estritamente à esfera virtual. Os indivíduos, embora muitas vezes estejam afastados de uma relação mais aproximada entre si, não perdem o contato relacional e o sentimento para com as pessoas que com eles convivem. O que interessa ressaltar é que, na esfera virtual, a sociabilidade é travada mediante a troca de intimidades, sendo nestas relações que os sujeitos buscam construir seus elos de convívio virtual.

É nesse aspecto que os laços de sociabilidade realizados no contexto virtual realizase aquém do debate ideológico-político que, quando inaugurado num meio flexível e instável como o ciberespaço, as discussões políticas parecem findar na ordem do discurso, e o sujeito, ao demonstrar interesse nessa questão, o faz, na maioria das vezes, para agregar valor à sua personalidade. Contudo, para se realizar afirmações mais acertadas sobre esse aspecto, é necessário um estudo que leve em consideração a ordem das expressões e debates políticos que se realizam tendo como suporte as mídias virtuais. Não obstante, as práticas de publicação virtual também envolvem expressões plurais, que vão na contramão do discurso propagado pela mídia, o que pode, inegavelmente, contribuir para um debate mais amplo e mobilizador para questões sociais e políticas.

Inúmeras questões perfazem a discussão em torno das características que permeiam a chamada cibercultura, dentre elas, a exposição da intimidade e as novas formas de sociabilidade, o que torna complexo e parcial o entendimento desse fenômeno. As discussões aqui levantadas, portanto, referem-se à compreensão de algumas destas características e referenciais teóricos pertinentes à análise, visando contribuir com perspectivas para futuras abordagens.

\section{Referências Bibliográficas}

ARENDT, Hannah. A condição humana. São Paulo: Forense Universitária, 2005.

BAUDRILLARD, Jean. Tela Total: mito-ironias do virtual e da imagem. Porto Alegre: Sulina, 2005. 
A sociedade de consumo. São Paulo: Martins Fontes, 1970.

BAUMAN, Zigmunt. Vida para o consumo: a transformação das pessoas em mercadoria. Rio de Janeiro: Jorge Zahar, 2008.

Em busca da política. Rio de Janeiro: Jorge Zahar, 2000.

A ética pós-moderna. São Paulo: Paulus, 1997.

BERGER; LUCKMANN. Modernidade, pluralismo e crise de sentido: a orientação do homem moderno. Petrópolis: Vozes, 2004.

COSTA, Jurandir Freire. Bernadet e o declínio do homem privado. In: Caderno de Psicanálise - CPRJ, n.14, Rio de Janeiro, 1994, p. 133-147. Disponível em: <http://jfreirecosta.sites.uol.com.br/>. Acesso em: 28 mar. 2009.

DEBORD, G. A sociedade do espetáculo. Rio de Janeiro: Contraponto, 1997.

GIDDENS, Anthony. Modernidade e identidade. Rio de Janeiro: Jorge Zahar, 2002.

As conseqüências da modernidade. São Paulo: Editora UNESP, 1991.

GOFFMAN, Erving. A representação do eu na vida cotidiana. 15 ed. Petrópolis: Vozes, 2008.

Behavior in public places: notes on the social organization of gatherings. New York:

The Free Press, 1966.

HABERMAS, J. Mudança estrutural da esfera pública: investigações quanto a uma categoria da sociedade burguesa. Rio de Janeiro: Tempo Brasileiro, 1984.

HARVEY, David. A Condição Pós-moderna. São Paulo: Loyola, 1992.

HALL, Stuart. Identidade cultural na pós-modernidade. Rio de Janeiro: DP\&A, 2000.

JOVCHELOVITCH, Sandra. Representações sociais e esfera pública: a construção simbólica dos espaços públicos no Brasil. Petrópolis: Vozes, 2000.

LASCH, C. A cultura do narcisismo: a vida americana numa era de esperanças em declínio. Rio de Janeiro: Imago, 1983.

LIPOVETSKY, Gilles. A era do vazio: ensaios sobre o individualismo contemporâneo. São Paulo: Manole, 2005.

Barcarolla, 2004.

Os tempos hipermodernos. Tradução de Mário Vilela. São Paulo: Editora

PROST, Antoine. Fronteiras e espaços do privado. In: PROST, A.; VINCENT, G. (Orgs.). História da vida privada: da primeira guerra a nossos dias. Vol. 5. São Paulo: Companhia das Letras, 2009. 
ROCHA, Aline M. Matos. Leituras da cibercultura: reflexão crítica sobre os diários íntimos na Internet. Fortaleza: 2006. Monografia apresentada como pré-requisito para conclusão do Curso de Ciências Sociais - Universidade de Fortaleza.

RÜDIGER, Francisco. Cibercultura, filosofia da técnica e civilização maquinística: fundamentos da crítica ao pensamento tecnológico. In: ESCOSTEGUY, C. D. (Org.). Comunicação, cultura e mediações tecnológicas. Porto Alegre: EDIPUCRS, 2006.

Elementos para a crítica da cibercultura: sujeito, objeto e interação na era das novas tecnologias de comunicação. São Paulo: Hacker, 2002.

Subjetividade e novas tecnologias de comunicação: elementos para a crítica do pensamento contemporâneo. In: INTERCOM, 22. 2000. Disponível em: <http://www.intercom.org.br/papers/xxii-ci/gt10/10r05.PDF>. Acesso em: 21 jan. 2006.

SENNETT, Richard. O declínio do homem público: as tiranias da intimidade. São Paulo: Companhia das Letras, 1988.

SIBILIA, Paula. O show do eu: a intimidade como espetáculo. Rio de Janeiro: Nova Fronteira, 2008.

A intimidade escancarada na rede: blogs e webcams subvertem a oposição público/privado. In: $\quad$ Intercom $2003 . \quad$ Disponível <http://www.intercom.org.br/papers/congresso2003/pdf/2003_NP08_sibilia.pdf>. Acesso em: Fev. 2006.

THOMPSON, John B. A mídia e a modernidade: uma teoria social da mídia. 7. ed. Petrópolis: Vozes, 2005.

Ideologia e Cultura Moderna: teoria social crítica na era dos meios de comunicação de massa. Petrópolis, RJ: Vozes, 1995.

VIRILIO, Paul. Espaço crítico. Rio de Janeiro: Editora 34, 1999. 